\title{
The Hidden Repercussions of Microaggressions on Individuals in Higher Education
}

\author{
Emarely Rosa-Dávila ${ }^{1^{*}}$, PhD, Marta Mercado-Sierra ${ }^{2}$, PhD, Daniela Castillo Vazquez ${ }^{3}$, Jorge F. Figueroa ${ }^{4}$, PhD \\ ${ }^{1,3,4}$ Department of Social Work, Texas Woman's University, United States. \\ ${ }^{2}$ Department of Social Work, Texas A\&M Commerce, United States.
}

Article Details
Article Type: Review Article
Received date: $06^{\text {th }}$ August, 2020
Accepted date: $02^{\text {th }}$ September, 2020
Published date: $07^{\text {th }}$ September, 2020
$\quad$ Corresponding Author: Emarely Rosa-Dávila, PhD, Assistant Professor, Department of Social Work, Texas Woman's
University, P.O. Box 425887, Denton, TX 76204, USA. E-mail: erosadavila@twu.edu
Citation: Rosa-Davila, E., Mercado-Sierra, M., Castillo Vazquez, D., \& Figueroa, J.F. (2020). The Hidden Repercussions
of Microaggressions on Individuals in Higher Education. J Ment Health Soc Behav 2(2):124. https://oi.org/10.33790/jm-
hsb1100124
Copyright: $@ 2020$, This is an open-access article distributed under the terms of the Creative Commons Attribution License
4.0, which permits unrestricted use, distribution, and reproduction in any medium, provided the original author and source are
credited.

\section{Abstract}

Although higher education institutions have engaged in efforts on diversity, equity, and inclusion, members of marginalized or excluded groups on-campus experience microaggressions on a daily basis. This form of offense is detrimental to the individuals' emotional and psychological well-being. Research proves the impact on the mental health of targeted individuals and groups. The purpose of this paper is to examine how research has documented microaggressions' impact on the mental health of traditionally and non-traditionally excluded and marginalized populations in institutions of higher education instead of fostering social justice through stimulating and securing the well-being and worthiness of the community. To accomplish this task, we selected the research dated from 2003 to the first quarter of 2020 and conceptual articles specifically on microaggressions on the different community-campus groups identified by higher education. To explain this phenomenon, we use framework encompassed three perspectives: social responsibility principles of higher education from a human rights perspective, social construction theory, and a culturally grounded approach. As part of our final reflection we state emotional wounds caused by microaggressions can be tackled and mental health can be promoted by creating the ideal conditions for people to live in a state of well-being and develop and carry out a productive and satisfactory life project; where they have the right to an environment compatible with health and the right to be treated with dignity regardless of their race, gender identity, sexual orientation and/or disability.

Keywords: Microaggressions, Mental Health, Higher Education, Social Constructionism Culturally Grounded Approach, Structural Oppression, Social Justice

\section{Introduction}

In this historical moment, where thousands of individuals, mainly young adults, are hitting the streets throughout the United States of America (US) expressing their indignation on structural and institutional oppression and advocating for fundamental human rights of black and brown people, universities are being held accountable on their social responsibility by their campus communities. It is time to rethink and adopt strategies to dig deep into our organizational culture to transform our everyday interactions that are costing a human toll within our institutions; thus, communities and the greater society. Although higher education institutions have engaged in efforts on diversity, equity, and inclusion, members of marginalized or excluded groups on-campus experience microaggressions on a daily basis.
According to Sue et al. [1], microaggressions are contemporary forms of implicit or explicit biases expressed or presented subtly and briefly communicating hostile, derogatory, or harmful smears on a daily basis to an individual or group based on their social status. Although these behaviors and practices are ephemeral and usually imperceptible by the transgressor and other privileged individuals present during the interaction, it does not mean it goes unnoticed by the target person or group. This form of offense is detrimental to the individuals' emotional and psychological well-being. Research proves the impact on the mental health of targeted individuals and groups. The literature also discusses how the act and the effect of microaggressions perpetuate the systems of oppression in place, protecting privileged groups status and limiting the opportunities and access to resources to groups of the population considered undeserving based on their cultural identities [1-3] and hierarchy status.

Higher education institutions are one of the more noteworthy contexts in which everyday microaggressions are delivered through verbal, non-verbal and symbolic means of communication. It is understood that microaggressions take center stage in the socialization process and certainly in hierarchical institutions [2, 4] as universities and colleges. Marsiglia \& Kulis [5] affirm universities have an acculturative effect on the members of their community contributing to the assimilation of individuals to the dominant culture. On the other hand, this same social institution has the responsibility of preparing qualified workers and leaders engaged with the constant and dynamic reformation of societies towards a vision that reflects the values of human rights and the sustainable development of communities [6]. How can institutions of higher education comply with this social demand when, on the contrary, it contributes to diminishing the mental health of students, faculty, staff, including managerial personnel, not addressing microaggressions on campus?

Based on the above, phenomenon, the purpose of this paper is to examine how research has documented microaggressions' impact on the mental health of traditionally and non-traditionally excluded and marginalized populations in institutions of higher education instead of fostering social justice through stimulating and securing the well-being and worthiness of the community. The paper aims to specifically:

- $\quad$ explore manifestations of microaggressions in higher education (students, faculty, staff) in the existing literature; 
- $\quad$ identify non-traditional marginalized or excluded populations based on physical appearance, body shape, age, first-generation students, within others, also experiencing microaggressions in research; and

- describe microaggressions' impact on individuals' mental health participating in campus life through existing literature.

This article pertains to further contribute to the body of knowledge of microaggressions as a social mechanism in higher education that perpetuates oppression beyond the walls of the "ivory tower" through the weakening of the mental health of already culturally distressed members with non-dominant identities in our society that participate in campus life. To accomplish this task, we first identify sources of information using the following keyword combinations: microaggressions + unconscious bias, microaggressions + mental health, microaggressions + higher education, microaggressions + classroom; and microaggressions + faculty through our universities' libraries and google scholar search engines. Then we selected the research dated from 2003 to the first quarter of 2020 and conceptual articles specifically on microaggressions on the different communitycampus groups identified by higher education. We did not consider research on a single race, ethnicity, gender, or sexual identity. We focused on research based on varying levels of interactions within a campus community to identify all marginalized or excluded populations. The findings in the literature review describe how everyday microaggressions in higher education settings not only impact the mental health of participants but also how these dynamics promote, sustain and foster the ideas, values, beliefs of the dominant culture within higher education perpetuating an oppressive society. The pillars of social justice and anti-oppression guided the reflections of this phenomenon.

\section{Theoretical Framework}

The framework encompassed three perspectives: social responsibility principles of higher education from a human rights perspective, social construction theory, and a culturally grounded approach. This framework facilitates the understanding, description, and analysis of the impact of microaggressions on the emotional and psychological health of individuals within the context of higher education from their cultural identities.

The social construction theory explains the process of socialization and construction of worldviews, the interaction of universities' group members, and the impact and implications of unconscious bias, thus microaggressions on the mental health of traditional and non-traditional minority populations. To discuss microaggressions' impact on the population and analyze implications, we subscribed to a culturally grounded approach. The integration of these concepts facilitates the reflection on how not only microaggressions impact the mental health of individuals in higher education, but also, how these types of interactions contribute to long term effects.

Higher education is one of the leading social institutions that contribute to the constructions of worldviews and where cultural ideas, values, and beliefs are put to the test through interactions with diverse individuals and the campus environment. Tertiary education is principally responsible for preparing future leaders, entrepreneurs, service providers [7], scientists, artists, within other occupations to sustain the social, cultural, economic, and political development. Their main goal is to prepare academically young adults for the world, educating them in disciplines to embark in professional settings and their communities. Through this andragogy process, individuals exchange different cultural ideas, values, and beliefs through their interactions and that compete.

Tibbits [6] understands that universities have a role to play in society beyond preparing students to become knowledgeable and skilled workers. Universities should engage students as individuals involved with the constant formations and reformation of society based on human rights. The United Nations' Sustainable Development Goal 4 of the 2030 Framework for Action (FFA) agenda (United Nations' Educational, Scientific and Cultural Organization's [7], aims to "ensure inclusive and equitable quality education and promote lifelong learning opportunities for all." This international organization calls upon higher education to reaffirm these principles. Based on these principles, UNESCO established education institutions uphold the following standard:

- Availability- to make education at all levels affordable to reduce inequality

- Accessibility- to make education accessible to all diverse populations, including but not limited to ableness, gender and sexual orientation, spiritual preference, immigrants, refugees, first generation students, within other social categories

- Acceptability- to make environment (classrooms, corridors, institutional culture), curriculum, policies, and practices relevant, non-discriminatory, culturally appropriate and of high quality

- Adaptability: to adapt to keep higher education relevant and dynamic, preparing students to tackle society's changing needs and issues $[6,8]$.

In summary, a non-discrimination principle should apply to all levels of education, including higher education [6]. Based on this institutional responsibility, UNESCO reaffirmed that universities should ensure to: contribute to human development and the progress of society, contribute to lifelong learning, treating students fairly and justly, adopt policies and procedures to ensure the equitable treatment of women and minorities and to eliminate sexual and racial harassment; and not impede professors classroom work and research by violence, intimidation or harassment.

By constructing knowledge through science, determining what is true and what is false within disciplines, and disseminating the information through language, universities exist as centers of power $[3,9]$. The use of language, written, verbal and symbolic, facilitates the description and explanation of social phenomena and interactions with others and the environment, one of the primary functions of science. As a center of power, universities are settled within and respond to the interests primarily of dominant groups, thus recreating the worldview through what Foucault [10] defines as disciplinary regimes. These domesticating regimes resemble and carry on the socialization process through verbal, non-verbal, and symbolic language we began as infants predominantly through the family and education systems. Western universities, from a Eurocentric platform, generates language, describes, classifies, and sets explanations for all disciplines, thus normalizing behaviors, setting legitimacy and truth, and the expectations for every individual [10].

The three fundamental principles of social constructionism are that knowledge is socially constructed, language is central to social construction, and that primarily the dominant group politically drives the construction of knowledge [3]. A specific context determines the interpretations and meanings of language, symbols, and interactions. Thus, interpretations and meanings do not necessarily reflect the reality of all individuals. This optic provides the opportunity to identify and comprehend diverse realities, coexisting worldviews. These realities are constructed through interactions within individuals and with the natural environment using language and symbols [3]. Social constructionism assumes that interactions within a given context determine the interpretation; thus, the meaning is socially constructed. Social constructionism establishes and draws from the assumption that all meanings are socially constructed through interactions within a given context.

Through relationships, we adopt, construct, and define the world; good and evil, just and unjust, inclusion and exclusion, within other dichotomies. Based on this perspective, our identities are influenced 
and, at the same time, considered, defined, and represented by others through language. Thus, our identity is under siege daily through our interactions. These relations are based on power $[2,3,5,10,11]$. These dynamics give rise to stereotypes and biases, constructing realities affecting particularly non-dominant groups. Foucault [10] understands that people readily subjugate themselves to subtle forms of power in their daily life. Others resist challenging the oppressor and others align with those in power. Although all take a toll on peoples' well-being, the latter actively contributes to perpetuating inequalities and all forms of oppression [5]. Freire [12] called denial of one's culture or identity, promoting the power of the oppressor, reifies the oppressive structure and then seeks freedom and power within the same structure he called internalized oppression. Since the individual from the minority group has been dehumanized and devalued, the oppressor becomes the model of humanity and worth emulating. These coping mechanisms brought forth by the oppressive structure solidifies the dominant culture; however, through these power dynamics in everyday interactions, it also develops crevices within the structure.

Thus, social constructionism legitimizes competing values in society, it recognizes that strong adherence to own worldview leads to eradicating the other; on the other hand, it provides the opportunity to work across conflicting realities; and facilitates transformative dialogue towards collaborative construction of future reality [3]. Marsiglia \& Kulis [5] coincide with Gergen in the understanding of a potential collectivistic view of the world through those crevices.

From a culturally grounded approach, Marsiglia \& Kulis [5] also assert, "Culture is both an outcome and a process that arises from meaningful interactions of people." (p. 3). Culture influences the construction of self, as each individual adopts ideas, values, believes, and behaviors from the dominant culture at different levels of adherence forming varied worldviews. The diverse worldviews and the daily interactions create a fissure for transformation. An assumption espoused by this approach is that interpretations on critical conversations of values, beliefs, and ideas change throughout time, thus culture is ever changing.

Another conjecture is that behaviors and practices are significant; when repeated continuously, they become the "backbone of culture" based on a symbolic value. On the other hand, opportunities for social change diminish at a higher level of adherence to the dominant culture. This approach acknowledges the existence of subtle assimilation strategies embedded in the dominant culture to eradicate cultural differences and preserve their ideas, values, beliefs, and practices.

It is understood that societies are made-up of more than one culture where one holds power over minority cultures. The coexistence of these cultures creates a system of social stratification where differences emerge creating boundaries and establishing levels of privilege and inequality, thus systems of oppression. Constructed social categories such as race, ethnicity, sex, class, age, ableness status, gender identity, sexual orientation, marital status, spirituality, serology status, and others socially constructed categories such as physical appearance, skin tone, credentials, language, within others are appraised based on the value established by the dominant culture.

A culturally grounded approach acknowledges the coexistence of multiple cultures, honors cultural boundaries, and finds effective ways to crossover cultures. Nevertheless, it recognizes that boundaries help uphold and perpetuate systems of oppression safeguarding the ideas, values, beliefs, and practices of the dominant culture [5]. Yet, assuming a culturally grounded approach allows us to analyze the dynamics of a phenomenon from all coexisting cultures, acknowledge their differences and power disparities. It also provides culturally centered principles to address the phenomenon from anti-oppressive, multicultural, and transformational approaches.

\section{Literature Review}

We cannot discuss microaggressions without addressing the socialization process every individual undergoes as soon as we take a breath out of the womb. Our ideas, values, beliefs, behaviors and worldview are conditioned by the interaction with individuals and the socio-economic-political and cultural environment.

Chugh [13], states that biases "are baked in culturally, legally and structurally" (p.43). As we consume these oppressive social manipulations through our socialization process, it becomes ingrained in our values, beliefs, consciously and subconsciously [3], creating stereotypes, prejudice, and biases. Sue et al. [1, 14] sustains how prejudice, stereotypes, and biases based on social categories exist on a continuum of conscious awareness. These biases, stereotypes and prejudices are foundation to discrimination and oppressive attitudes and behaviors as violence, exclusion, marginalization, exploitation [15].

Since the most visible macroaggressions are prohibited after the legal gains of the women's, civil rights, people with disabilities, and LGBTQ movements, the mainstream has socially recognized discrimination and oppression based on race, ethnicity, ableness, sex, sexual and most recent gender identities, microaggressions took center stage. Gillborn [16] denominated microaggressions as "hidden operations of power" and David \& Derthick [17] explained that it took a modern form constituting a new means of oppression.

In the legal jurisdiction, policies are in place to hold perpetrators accountable for microaggression, and higher education is not exempt from complying with these legal standards such as Affirmative Action, Title IX, Equal Opportunity, within others. On the other hand, microaggressions pass invisibly with no repercussions against the offenders. In no way, we minimize or ignore the reality that targeted groups are still experiencing explicit aggression against protected and not legally protected groups. Victims of microaggression are also distressed and harmed by everyday events. The term microaggression was first introduced by Pierce, et al. [18] as "subtle, stunning, often automatic, and non-verbal exchanges which are 'put downs' of blacks by offenders" (p. 66). They meant "micro" to "everyday" not because it is considered lesser or inconsequential [4]. Sue et al. [19] ample the definition to include other minority groups and specified other means of microaggressions as verbal and environmental and proposed that they also stemmed from unconscious bias. Sue et al. [14] then broadened the phenomenon describing it as "implicit or explicit ...hostile, derogatory, or negative slights, invalidations, and insults to an individual or group because of their marginalized status in society" covering other traditionally oppressed populations.

Berk [2] enhances the definition by specifying the populations targets of microaggressions. Besides race, ethnicity, gender and sexual identity, he includes nationality, culture, religious beliefs, mental and physical abilities, socio-economic status, age generation oy intersections of these. He also rejects that microaggressions are overt; if they are micro, they are implicit, native to unconscious biases, and expressed through verbal, non, verbal, symbolic, and environmental means. These aggressions manifest through microinsults, micro-assaults, and micro-invalidation [1]. However, Berk does not acknowledge micro-assaults as micro-aggressions due to the perpetrator's overt, conscious, and intentional act.

Microaggressions often originate from people who are mostly well-intentioned people. Nevertheless, this does not make their interaction harmful to the well-being, self-esteem and standards of living of people who experience it [13, 20]. Berk [2], states that microaggressions are not only constant, continual and cumulative but also corrosive (p.68). This phenomenon occurs in all social institutions including university campuses. Research has documented different levels of interaction where microaggressions occur on a daily basis in this social institution. 


\section{Microaggressions and Mental Health in Higher Education}

For this article's purpose, mental health is defined as a state of well-being in which every individual realizes his or her potential, can cope with the normal stresses of life, can work productively and fruitfully, and contribute to her or his community [21]. It affects how people think, act, handle stress, and make choices. How people handle this state of well-being depends on how their reality is socially constructed. In this positive sense, mental health is the foundation of individual well-being and effective community functioning.

Foucault [10] conceived of mental illness as arising from the contradiction between the structures of social experience and the lucid awareness of these contradictions. Mental health is also maintained due to the person's capacity to design goals and life projects [22], and the ability to gather the necessary resources to achieve such plans. The person has to partake full participation in the achievement of their life projects. However, when microaggressions are in the picture, it is difficult for the victims to feel a sense of belonging in the community. Consequently, they may put their goals on hold because the oppressive systems make available and necessary resources seem inaccessible and the person feels that they do not deserve the opportunity to access those resources. Why are people's mental health affected by microaggressions?

Just as the socialization process builds our reality, when the dominant ideology is different from our referent, the individual's mental health is greatly affected. When traditionally excluded minorities internalize the discourse of the dominant ideology, they could internalize it so that they live in continuous and internalized oppression. The Dog Whistle Politics is an example of this dominant ideology and its effect on mental health. This example is a political message that uses coded language that seems to mean one thing to the general population, but has additional, different, or more specific resonance for a group (Haney-Lopez, 2015). This encrypted message is used to maintain and perpetuate oppression. Here are some examples used in different speeches by the 45th and current President of the United States of America: Dog Whistle Politics coded messages

- "We speak English here, not Spanish.” - September 23, 2015

- "He should really set an example by speaking English in the United States." - September 2, 2015

- "I think it is more appropriate to speak in English." - September 3,2015

- "This is a country where we speak English." - August 23, 2016

- "We have a country where to assimilate; you have to speak English." - September 1, 2016

- " "He actually speaks very good English." - August 26, 2016

- “He speaks perfect English.”- August 20, 2018

Microaggressions are especially stressful because their subtle character makes them socially legitimized. The intensity and the dayto-day repetition of microaggressions is what determines the level of harm to the victim $[1,23]$, which means that these subtle but common discriminations damage the targets emotional and psychological well-being.

As mentioned priorly, these microaggressions manifest as microinsults, micro-assaults, or microinvalidations.

\section{Microinsults}

This type of microaggression [2] attacks a person's intelligence, competence, or capabilities, which are rude or insensitive behaviors or statements. Nadal, K., et al. [24] that degrade a person's heritage or racial identity. Microinsults [1] convey stereotypes, rudeness, and insensitivity and that demean a person's racial, gender, or sexual orientation, heritage, or identity. They also represent subtle slights, often outside the perpetrator's consciousness, but they often convey a hidden insulting message to the victim. Some witnessed examples of microinsults are:

- "You have a strong accent, but your vocabulary is impressive." - to a Hispanic/Latina Assistant Professor.

- " $\quad$ That food looks disgusting." - to a Hispanic/Latina Assistant Professor who brought food from her home country for lunch.

- "You are so beautiful for an African American" - to a Social Work student on a university campus.

- Continuing to mispronounce the names of students after students have corrected the person time and time again. Not willing to listen closely and learn the pronunciation of a nonEnglish based name." [25].

- "Do you need someone to translate that for you?" - to a Hispanic/Latina Assistant Professor who asked for clarification in a meeting.

\section{Micro-assaults}

Micro-assaults are deliberate, subtle, or explicit biases, attitudes, beliefs, or behaviors communicated to marginalized groups through environmental cues [26, 27], verbalizations or behaviors. They are intended to harm the person's group identity or attack / injure the victim affected by insults, avoidance behaviors, or intentional discriminatory actions. It is the most overt form of microaggression. Some examples of micro-assaults are:

- The use of racial epithets: referring to African Americans as "niggers," Chinese Americans as "chinks," Japanese Americans as "Japs," women as "bitches" or "cunts," and gays as "fags." Again, the intent is to assail one's racial, gender, or sexual identity and to communicate to the recipient that they are "lesser human beings." [1]

- Telling a Latina or Black daughter "You have to improve our race.", meaning she needs to marry a white man to make her future children worth it.

\section{Microinvalidations}

Microinvalidations are characterized by environmental signals or communications that exclude, deny, or nullify the psychological thoughts, feelings, or experiential reality $[1,28]$ of certain groups, such as people of color. In many ways, microinvalidations may represent the most damaging form of the three microaggressions because they directly and insidiously deny the racial, gender, or sexual orientation reality of these groups. Some examples of microinvalidations as follow:

- The theme of Color Blindness occurs when people deny a person's experiences regarding race; for instance, when people make comments like "America is a melting pot" or "There is only one race, the human race," they are denying the other's racial reality [28].

- The Ascription of Intelligence theme refers to labeling someone with a certain amount of intelligence based on her or his race (e.g., assuming that Asian Americans are good at math or sciences or that Black people are not intelligent or educated) [28].

These micro-aggression experiences are linked to mental anguish, poor self-esteem, and costs to academic success among minority college students $[24,29]$. Literature has documented the adverse impact of institutional racism and open interpersonal racial discrimination on the lives of excluded or marginalized people. Research shows that individual perception of events as discriminatory or racist can have traumatic effects on psychological well-being [30, 31]. Racism is linked to illnesses such as substance abuse [32], low self-concept and self-esteem [33], mental anguish [34], and signs of depression [35]. In another research study, Pascoe and Richman [36] found that perceived discrimination had a significant adverse effect on both 
mental and physical health and is related to participation in unhealthy behaviors and non-participation in health. When individuals perceive and experience discrimination in their personal lives, damaging impacts on their well-being and mental health arise. Research on internalized oppression suggests that individuals who experience oppression develop signs and symptoms such as rumination, negative self-schemas, and feeling of hopelessness [17], increasing for the oppressed individual to be clinically diagnosed with a mental health disorder or to engage themselves in high-risk behaviors [37].

According to Nadal et al. [28], higher levels of cumulative experiences of racial microaggressions predicted depressive symptoms and one's affect. People experiencing second-class citizens, invalidation, and labeled as different or exotic, not conforming to the dominant culture, had adverse mental health symptoms.

Nadal et al. [28] research study results indicate that experiences of microaggressions may correlate with specific mental health problems, such as depression and lack of positive affect. This particular study demonstrates the relationship between racial microaggression and mental health is significantly harmful. Possibly, people who perceive and experience racial microaggression in their lives have negative mental health symptoms such as depression, anxiety, bleak worldview, and poor behavioral control skills. Forrest-Bank et al. [38] research study also shows that racial microaggressions have a negative impact on the emotional health of young adults from racial and ethnic minorities. On the other hand, micro-aggressive experiences can also provoke a stronger ethnic identity, which seems to serve as a protective factor against the negative influence of microaggression on psychological well-being.

\section{Discussion}

Many US universities have adopted this discourse through policies such as Title IX, Affirmative Actions, establishing multicultural programs and centers, diversity, equity and inclusion committees, supporting academic programs on diverse cultural populations, promoting student, faculty, and staff collectives based on cultural diversity and shared experiences. However, the debates on oppression and discrimination of individuals and groups identified based on social categories from culturally undervalued have not diminished significantly. Contrary, these populations continue to be targets of macro and microaggressions, including discrimination in higher education [19]. According to Berk [2], microaggressions challenge diversity and inclusion practices on campus. It is not surprising that FFA calls upon the tertiary education system to improve access, equity, quality, and relevance by 2030 .

We must see faculty and students as complex human beings that fulfill different roles in life. When one of the areas of their life is affected, it is like a domino effect. When we talk about the fact that the person's mental health is affected by the microaggressions received, we must consider the possibility that this affects one or more areas in their lives. These effects are evident in students' change in mood, lack of tolerance toward other students, course absenteeism, within others, particularly on campus. The level of stress and anxiety triggered on campus can affect faculty and student relationships, although it will impact the family, employment, and other relationships in their community. Universities have the responsibility to provide education in a safe and welcoming environment where people feel that they belong. Despite this, many individuals from minority groups in higher education do not feel included or welcome.

The fact is that members of cultural minorities do not have the privilege of forgetting their cultural background [5], as their interactions impact their daily life (thoughts, conversations, interactions), and reminds them of how different they are within the context. "Each small race-related slight, hurt, invalidation, insult, and indignity rubs salt into the wounds of marginalized groups in our society." [1]. People cannot change the color of their skin nor heritage.
Everyone has their own story, and for minorities, that story can hinder their life due to microaggressions. For example, it is not uncommon for first-generation Hispanic parents in the US to avoid speaking Spanish to their children at home. They want their children to fit in, to assimilate to the culture. Not because parents do not value their heritage, but because they do not want the children to suffer discrimination for not knowing English. Also, most of our Hispanic college students shared how hard they worked to learn English in elementary school. Some have shared in class, "I was bullied because of my accent.", "I was called a spik", and "I worked so hard to pronounce everything right".

Sue [39] explained this state by arguing that microaggressions are connected to a sociopolitical environment of oppression that can lead to trauma, resulting in emotional wounds that cross over generations of those who lived and are experiencing stories of discrimination and prejudice. Microaggressions highlight cultural differences in such a way that the person who receives the aggression feels anguish, anxiety, and a sense of not belonging. For example, when in college, a fellow student or colleague expresses concern about a person of color's competence in the mastery of English, questions its presence in the institution even more markedly so that it makes it the widest gap and keeps excluded marginalized people isolated. Individuals begin to doubt their abilities due to experiences like microaggressions. Research establishes a relationship between microaggression experiences on campus and psychological distress among college students [40]. Also, studies identified microaggression experiences evoke anger, frustration, and, if frequent, depression among individuals [41].

For minority students, higher education can bring added burden associated with racism and hostile campus climate as individuals transition to college [42]. If the student is a first-generation in college, it is more complicated the sense of belonging and feeling welcome and does not exist. According to Nadal et al. [43], when students encounter microaggressions, they immediately feel distress. The accumulation of such experiences will harm their well-being. They add a layer of anguish to their already oppressive experiences before arriving at college. How they see themselves and their life experiences influence and style of learning and how they experience university life. In other words, individuals have different learning experiences based on their constructed identity and experiences of overt and subtle racism (i.e., microaggressions) while differing selfefficacy beliefs and outcome expectations [44].

In the case of faculty experiencing microaggressions, they may begin to doubt their abilities and competencies to perform her or his work. These oppressive experiences may affect a person's perception regarding her or his professional projection. It can also affect the teaching style, active participation in different committees, and the overall duties and responsibilities. The professor may also feel disenfranchised due to not receiving support within the institution. The insecurity caused by the microaggressions experienced can lead the person not to trust the support system available in the institution. If the scholar feels that she or he cannot trust or vent the situation with the immediate supervisor, will the person feel confident to reach out to the dean? If colleagues or supervisors understand this person is feeling insecure, they are usually referred to the employee assistance program provided by Human Resources. Although a valid alternative, this strategy places the responsibility of insecurity and underperformance on the victim of microaggression, the professor. Instead of blaming the victim, we should hold the perpetrator accountable and promote an equitable and inclusive environment.

According to Hatzenbuehler [37], people understand that stigmatized individuals manage their tarnished social identity and have to make an intense effort to adapt their emotions, diminishing the resources necessary. This fractured social identity makes them more vulnerable and prone to developing complex mental health problems, such as 
depressive symptoms, anxiety, sleep difficulties, lack of confidence, helplessness, loss of drive, and intrusive cognitions (e.g., internal dilemma). Sue [1] explained these intrusive cognitions as followed:

- Did I interpret that correctly?

- Did she say what I think she said?

- What did he mean by that?

- Should I say something?

- Saying something may make it worse.

- They'll probably think I'm overreacting.

- Speaking up is going to hurt more than it helps.

Microaggressions not only harm mental and physical health, but can also threaten the trust in university service providers, faculty, students, colleagues, and the overall system. Microaggressions are symptoms of a broader structural problem. There is a need to call for accountability. The micro-aggressor must take responsibility for her or his behavior. Holding them accountable can help create more reflective and inclusive communications across all divisions of race, gender, sexual orientation, and gender identity. In general, it is crucial to understand that jokes related to race, gender, ethnicity, gender, and sexual identities within other identities are not acceptable. This type of jokes perpetuates existing racism and sexism, and while it may seem harmless and done unconsciously, it reinforces discrimination and prejudice and affects the mental health and well-being in anyone's study or workplace.

The limitations identified in this paper arise from the findings in the literature. As we worked on the literature review, we found substantial information regarding microaggressions towards African Americans and the LGBTQ population, impact on students' mental health, conceptual papers, and training outlines. Nevertheless, the research on the following was limited:

- research microaggressions and its effects on faculties mental health

- research on other minorities other than African American and Asian populations

- $\quad$ research on other known and not well-known manifestations of oppression as physical appearance, body shape

- research on offenders that sustain and participate in carrying out microaggressions

These limitations did not permit a profound analysis of some topics. However, these limitations facilitated the identification of gaps in the literature to propose research to fill the breaches. There is a need for research to focus on how structural oppression affects the traditionally excluded and marginalized minorities' mental health, but also about how this population arises from all that oppression. Regarding university settings, there is a need for researching how faculty and staff are affected by microaggressions at all levels. If carrying-out research on the perpetrators, we need to engage the university to assume responsibility, change or develop new policies, provide services, and take action by holding accountable whoever is responsible according to the study results. It is time to stop blaming the victim and make sustainable changes in the system.

\section{Final Reflections}

Microaggressions are present at all levels, from the micro to the mezzo and the macro. Due to the socialization process, these unconscious biases pass from one generation to the next. People construct their reality based on the experiences within the environment and the context they lived. Transformative dialogue needs to be addressed at all levels to form a microaggression-free society successfully. This kind of society is desired for the next generations; we need to do better to achieve it.

A way to achieve this is through the social institution of higher education. Thus, universities transmit ideologies through education. Through language, universities deliver science; science is considered truth. We need to differentiate natural science from human science.
Although we recognize they interact and depend on each other, we focus on human relationships, which crosses through all areas of academic sciences. We are referring to the development of social beings. Let us take that privilege, create a reality which includes diverse people, and sell it to the world.

Universities also generate language to explain, describe classifications, explanations in all disciplines. Thus, normalizing certain behaviors, what is legitimate, what is truth, what is right, in other words, what is, and what to expect of each individual. Higher education is the last opportunity to socialize in a formal social institution. Thus, it is the last opportunity to deconstruct and reconstruct our social reality.

First, higher education administration needs to create the climate and send a message on what is sanctioned and what is not. How the message is expressed will reflect campus ideology and the power of feelings. Universities' position on the subject reflects their values. Second, they must hold people accountable. Create the climate to resocialize. Then, provide transformative opportunities to all the parts offering strategies and skills. This will finally impact the studentsoffering a robust learning and transformative community where the university performs their social responsibility.

Gergen [3], suggests to assign a higher value to the well-being of relationships and invest our energy on relationships, not on the individual. We achieve well-being through personal relationships and the environment. In this context, the university's commitment requires the ability to respond effectively to society's transformation needs, in which it is immersed, through the exercise of its essential functions: teaching, research, and social extension/projection [45]. These functions must be supported by searching for the promotion of justice, solidarity, and social equity, through the construction of successful responses to address the challenges of promoting integral human development.

There are cracks in the system that can foster a more just and inclusive society. Emotional wounds caused by microaggressions can be tackled, and mental health promoted by creating the ideal conditions for people to live in a state of well-being. Thus, develop and carry out a productive and satisfactory life project, where they have the right to an environment compatible with health and the right to be treated with dignity regardless of their race, gender identity, sexual orientation, and abilities. Let us not continue serving the people who experience oppression; let us start confronting the faces of oppression. Let us continue the conversation about privilege and how we can use it to crack the foundation of oppression, our socialization. Let us awake more inquiries within the university structure to contribute to a more just, inclusive, and empathetic society embracing diversity and difference. The mental health impact on all the parts makes it necessary for higher education to assume and engage in their social responsibility to contribute to a more equitable and just society.

Conflicts of interest/Competing interests: Authors report no conflict or competing interest.

\section{References}

1. Sue, Derald Wing. (2010) Microaggressions in Everyday Life : Race, Gender, and Sexual Orientation, John Wiley \& Sons, Incorporated,2010. ProQuestEbook Central,http://ebookcentral. proquest.com/lib/texaswu/detail.action?docID $=487711$.

2. Berk, R. A. (2017). Microaggressions trilogy: Part 1. Why do microaggressions matter? The Journal of Faculty Development, 31(1), 63-73.

3. Gergen, K. J. (2009). An invitation to social construction (2nd ed.). Sage Publications Ltd.

4. McTernan, E. (2018). Microaggressions, equality, and social practices. The Journal of Political Philosophy, 26(3), 261-281. 
5. Marsiglia, F. F., \& Kulis, S. (2015). Diversity, oppression, and change: Culturally grounded social work (2nd ed.). Oxford University Press.

6. Tibbits, F. (2020). Emancipatory Human Rights and Higher Education. [Webinar]. UNESCO-IESALC.

7. UNESCO (2020). Leading SDG 4 - Education 2030. Retrieved from https://en.unesco.org/themes/education2030-sdg4

8. Duncan, W. (2004). A Human Rights contribution to defining quality education. United Nations Educational, Scientific and Cultural Organization (UNESCO).

9. Foucault, M. (1979). Enfermedad mental y la personalidad. Paidós.

10. Foucault, M. (1979). Discipline and punishment: The birth of the prison. Vintage.

11. Freire, P., \& Ramos, M. B. (1970). Pedagogy of the oppressed. Continuum.

12. Freire, P., Freire, A. M. A., \& Freire, P. (1994). Pedagogy of hope: Reliving pedagogy of the oppressed. Continuum.

13. Chugh, D. (2018). The person you mean to be: How good people fight bias. Harper-Collins.

14. Sue, D. W. (2014, September 16). Microaggressions and marginality: Manifestation, dynamics, and impact [Keynote Address]. Penn State University, State College, PA.

15. Young, Iris M. (1988). Five faces of oppression. Philosophical Forum 19 (4):270.

16. Gillborn, D. (2008). Racism and education coincidence or conspiracy? Abingdon: Routledge.

17. David, E. J. R., \& Derthick, A. O. (2014). What is internalized oppression, and so what? In E. J. R. David (Ed.), Internalized oppression: The psychology of marginalized groups (p. 1-30). Springer Publishing Company.

18. Pierce C., Carew J., Pierce-Gonzalez D., Willis D. (1978). An experiment in racism: TV commercials. In Pierce C. (Ed.), Television and education (pp. 62-88). Beverly Hills, CA: Sage.

19. Sue, D. \& Capodilupo, Ch. \& Torino, G. \& Bucceri, J. \& Aisha, \& Nadal, K. \& Esquilin, M. (2007). Racial microaggressions in everyday life: Implications for clinical practice. The American Psychologist. 62. 271-86. 10.1037/0003-066X.62.4.271.

20. Sue, D. W. (2005). Racism and the conspiracy of silence. The Counseling Psychologist, 33, 100-114.

21. World Health Organization. (2020). WHO urges more investments, services for mental health.

22. Rosa-Dávila, E. (2011). Salud mental comunitaria en los servicios del gobierno de Puerto Rico (1993-2008). (Publication No. 126648990) [Doctoral Dissertation, University of Puerto Rico). Semantic Scholar.

23. Volk, A. A., Dane, A. V., \& Marini, Z. A. (2014). What is bullying? A theoretical redefinition. Developmental Review, 34(4), 327-343. https://doi.org/10.1016/j.dr.2014.09.001

24. Nadal, K. L., Wong, Y., Griffin, K. E., Davidoff, K., \& Sriken, J. (2014). The adverse impact of racial microaggressions on college students' self-esteem. Journal of College Student Development, 55(5), 461-474. https://doi.org/10.1353/csd.2014.0051

25. UCLA (2014). Diversity in the classroom. Retrieved from https://equity.ucla.edu/wp-content/uploads/2016/06/ DiversityintheClassroom2014Web.pdf

26. Miller, J. \& Garran, A. (2008). Racism in the United States:Implications for the helping professions. Thomson Brooks/Cole.
27. Nelson, T. D. (2006). The psychology of prejudice. Pearson.

28. Nadal, K. L., Griffin, K. E., Wong, Y., Hamit, S., \& Rasmus, M. (2014). The impact of racial microaggressions on mental health: Counseling implications for clients of color. Journal of Counseling \& Development, 92(1), 57-66. https://doi. org/10.1002/j.1556-6676.2014.00130.x

29. McCabe, J. (2009). Racial and gender microaggressions on a predominantly-White campus: Experiences of Black, Latina/o and White undergraduates. Race, Gender \& Class, 16(1/2), 133151.

30. Lambert, S. F., Herman, K. C., Bynum, M. S., \& Ialongo, N. S. (2009). Perceptions of racism and depressive symptoms in African American adolescents: The role of perceived academic and social control. Journal of Youth and Adolescence, 38(4), 519-531. https://doi.org/10.1007/s10964-009-9393-0

31. Whitbeck, L. B., McMorris, B. J., Hoyt, D. R., Stubben, J. D., \& LaFromboise, T. (2002). Perceived discrimination, traditional practices, and depressive symptoms among American Indians in the upper Midwest. Journal of Health and Social Behavior, 43(4), 400-418. https://doi.org/10.2307/3090234

32. Gibbons, F. X., Gerrard, M., Cleveland, M. J., Wills, T. A., \& Brody, G. (2004). Perceived discrimination and substance use in African American parents and their children: A panel study. Journal of Personality and Social Psychology, 86(4), 517-529. https://doi.org/10.1037/0022-3514.86.4.517

33. Nyborg, V. M., \& Curry, J. F. (2003). The impact of perceived racism: Psychological symptoms among African American boys. Journal of Clinical Child \& Adolescent Psychology, 32(2), 258-266. https://doi.org/10.1207/s15374424jccp3202_11

34. Williams, D. \& Neighbors, H. \& Jackson, J. (2003). Racial/ Ethnic discrimination and health: Findings from community studies. American Journal of Public Health. 93(2). 200-208. doi: 10.2105/AJPH.93.2.200.

35. Schulz, A. J., Gravlee, C. C., Williams, D. R., Israel, B. A., Mentz, G., \& Rowe, Z. (2006). Discrimination, symptoms of depression, and self-rated health among African American women in Detroit: Results from a longitudinal analysis. American Journal of Public Health, 96(7), 1265-1270. https:// doi.org/10.2105/ajph.2005.064543

36. Pascoe, E. A., \& Smart Richman, L. (2009). Perceived discrimination and health: A meta-analytic review. Psychological Bulletin, 135(4), 531-554. https://doi.org/10.1037/a0016059

37. Hatzenbuehler M. L. (2009). How does sexual minority stigma "get under the skin"? A psychological mediation framework. Psychological Bulletin, 135(5), 707-730. https://doi. org/10.1037/a0016441

38. Forrest-Bank, S. S., \& Cuellar, M. J. (2018). The mediating effects of ethnic identity on the relationships between racial microaggression and psychological well-being. Social Work Research, 42(1), 44-56. https://doi.org/10.1093/swr/svx023

39. Sue, D. W. (2003). Overcoming our racism: The journey to liberation. Jossey-Bass.

40. Woodford, M. R., Joslin, J. Y., Pitcher, E. N., \& Renn, K. A. (2017). A Mixed-methods inquiry into trans* environmental microaggressions on college campuses: Experiences and outcomes. Journal of Ethnic \& Cultural Diversity in Social Work, 26(1-2), 95-111. https://doi.org/10.1080/15313204.201 6.1263817

41. Nadal, K. L., Issa, M.-A., Leon, J., Meterko, V., Wideman, M., \& Wong, Y. (2011). Sexual orientation microaggressions: "Death by a thousand cuts" for lesbian, gay, and bisexual youth. Journal of LGBT Youth, 8(3), 234-259. 
42. Locks, A. M., Hurtado, S., Bowman, N. A., \& Oseguera, L. (2008). Extending notions of campus climate and diversity to students' transition to college. Review of Higher Education: Journal of the Association for the Study of Higher Education, 31(3), 257-285. https://doi.org/10.1353/rhe.2008.0011

43. Nadal, K. L. (2018). Microaggressions and traumatic stress: Theory, research, and clinical treatment. American Psychological Association. https://doi.org/10.1037/0000073-000
44. Bonifacio, L., Gushue, G. V., \& Mejia-Smith, B. X. (2018). Microaggressions and ethnic identity in the career development of Latina college students. The Counseling Psychologist, 46(4), 505-529. doi:10.1177/0011000018776909

45. Beltrán-Llevador, J., Íñigo, E. \& Mata, A. Social responsibility of universities: The challenge of its continuous construction. (2014). Revista Iberoamericana de Educación Superior, 5(14), 3-18. doi: 10.1016/S2007-2872(14)70297-5 